University for Business and Technology in Kosovo

UBT Knowledge Center

UBT International Conference

2012 UBT International Conference

Nov 2nd, 9:00 AM - Nov 3rd, 5:00 PM

\title{
Performative Energies and Cultures: Ornament and (as) Structure
}

Banush Shyqeriu

University for Business and Technology, banush.shyqeriu@ubt-uni.net

Follow this and additional works at: https://knowledgecenter.ubt-uni.net/conference

Part of the Architecture Commons

\section{Recommended Citation}

Shyqeriu, Banush, "Performative Energies and Cultures: Ornament and (as) Structure" (2012). UBT International Conference. 2.

https://knowledgecenter.ubt-uni.net/conference/2012/all-events/2

This Event is brought to you for free and open access by the Publication and Journals at UBT Knowledge Center. It has been accepted for inclusion in UBT International Conference by an authorized administrator of UBT Knowledge Center. For more information, please contact knowledge.center@ubt-uni.net. 


\title{
PERFORMATIVE ENERGIES AND CULTURES: Ornament and (as) Structure - New Biological Paradigm
}

\author{
Banush Shyqeriu ${ }^{1}$ \\ ${ }^{1}$ Lecturer at Faculty of Architecture, University of Business and Technology in Prishtina; PhD Candidate and Researcher at \\ Institute for Cultural Sciences, Humboldt University in Berlin \\ banush.shyqeriu@ubt-uni.net
}

\begin{abstract}
Recently a great concern and interest has risen on ornament, which pushes us to render back its genesis, its worse times and its new frontiers.

This paper will be presented through a methodology which employs historical, theoretical and cultural implications of ornament in Architecture, as well as the present interest and developments on it, in the scope of advances in design and emerging technologies. A key figure in this discourse is the $19^{\text {th }}$ century German architect Gottfried Semper. His interest in ornament, textile and tectonics through searching the origins of Art and Architecture, provides us with crucial facts for the new frontiers of ornament in relation to structure.

The theoretical background that Semper laid will be used to scrutinize the elaboration and the importance of textile and patterning in the articulation of Architecture as cultural performance.

Following this line, an interesting theoretical and aesthetic approach will be set in the cultural meaning and use of patterning and ornament in the Islamic Architecture and its potentials for new frontiers ornament becoming autogenic.

The new biological paradigm on advanced design, sees building components as systems that act upon each other, where; material, structure, form, function and surface articulation / ornamentation are interconnected, similar to natural/biological systems with high performative energies. This paradigm provides new insights on ornament as structure itself, ornament as outcome of form, function and materialisation, far away from a mere superficial decoration. Further, natural/ biological systems grow highly hierarchical and optimized structures by using brittle and cheap materials, where the patterning of this structure serves their overall energetic performance.

Finally, this paper scrutinizes that the role of cutting-edge computational and production technologies is extremely evident in the materialisation of patterned and ornamented aesthetics and in the increased effectiveness of transfers of patterns from nature and biology into engineering and architecture. As a result, the significant emphasis on the structuring logic of tectonic is resulting in a 'new structuralism' in design, which, in turn emphasizes the role of performative cultures and energies of structuring architecture.
\end{abstract}

Keywords: Ornament; Structure; Cultural performance; Islamic Architecture; Biological paradigm; Performative energies

\section{Introduction}

Blinking weekly and strongly throughout the space and time, Ornament has always remained in the radar of attention of different disciplines, especially Art and Architecture; moreover, ornament was present since time immemorial. Recently a great concern and interest has risen on ornament, which pushes us to render back its genesis, its worse times and its new frontiers. 


\subsection{Origins of Ornament - a historical and theoretical approach}

The urge to ornament one's face, and everything in one's reach, is the origin of fine arts. ${ }^{4}$ Human kind since time immemorial used ornament both in their body and in their built forms, their structures and artifacts for daily use.

Alexander Speltz in the 'Styles of Ornament' dates the use of Ornament since Prehistory - 6000 years ago. Writing in the early $20^{\text {th }}$ century, Speltz takes an interesting position on describing Ornament in relation to Structure:

Rightly understood, the conformation of an ornament should be in keeping with the form and structure of the object which it adorns, should be in complete subordination to it, and should never stifle or conceal it.

...the art of ornamentation, therefore, stands in intimate relationship with material, purpose, form and style. ${ }^{5}$

Probably a more profound discourse on this issue we would fine in the writings of $19^{\text {th }}$ century German architect, Gottfried Semper, who was in a tensioned dilemma between continuity and innovation, a desire to struggle with both was evident for Semper, maintaining tradition while at the same time find genuine expressions for temporary culture. $^{6}$

The same idea of continuity we find in the work of Owen Jones 'The Grammar of Ornament':

To attempt to build up theories of art, or to form a style, independently of the past, would be an act of supreme folly. It would be at once to reject the experience and accumulated knowledge of thousand of years. On the contrary, we should regard as our inheritance all the successful labours of the past, not blindly following them, but employing them simply as guides to find the true path.

\subsection{Ornament and Structure}

Semper structured his investigation around the four primary elements or original motives of architecture: the wall (weaving), the hearth (ceramics), the mound (terracing and masonry), and the roof (carpentry).

In his treatise The Four Elements of Architecture (1851), Semper redefined the wall as a spatial enclosure, or 'wand', rather than as a structural and critical tectonic member ('mauer'). He referred to a building's envelope as an example of 'clothing' or "dressing" (Bekleidung) and found a common etymological root to the German words for 'dress' and 'wall' (Wand and Gewand). Likening textiles to built surfaces he described both as types of 'veiling'. For him it was the hanging wall-carpets and their status as nonstructural spatial dividers that made them 'the true walls, the visible boundaries of space'. 7 This archaeological and spatial theme suggests that the textile motive for the wall underwent an intricate process of formal development, as the conceptual rudiments of weaving evolved into textile wall hangings and later into solid wall dressings (panelling and paint) that emulated in style their original textile origin. ${ }^{8}$

Semper's depicting of his four elements is represented by the 'Caribbean hut' that he had encountered at the Great Exhibition of 1851 in London. The hut embodied in an exemplary way the four elements of architecture.

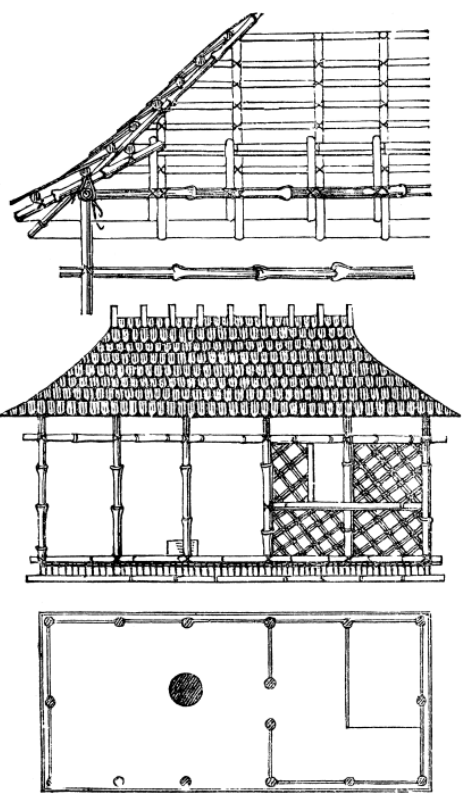

Figure 1.2.1: "The Caribbean Hut" (Source: Gottfried Semper, Der Stil (2 ${ }^{\text {nd }}$ ed.1879), vol. 2, p. 263)

Semper's structural / tectonic viewpoint in ancient and classical architecture would be better understood, when during the late 1830s, Karl Bötticher ${ }^{9}$ - on the advice of Schinkel - began to explore the ornamental forms of Greek

\footnotetext{
${ }^{4}$ Loos, A. (1998) 'Ornament and Crime: Selected Essays' trans. Michael Mitchell, Ariadne Press, Riverside, California, p. 29

${ }^{5}$ Speltz, A. (1923) 'Styles of Ornament' Regan Publishing Corporation, Chicago, 1923, p. 1

${ }^{6}$ Hvattum, M. (2004) 'Gottfried Semper and the problem of Historicism', Cambridge University Press, New York, p. 7

${ }^{7}$ Garcia, M. (2006) 'Prologue for a History and Theory of Architextiles', AD Vol 76/6, Wiley Academy, p. 15

${ }^{8}$ Mallgrave, H. F. (2006) 'Architectural Theory: An Anthology from Vitruvius to 1870' Blackwell Publishing Ltd., Oxford, p. 536

${ }^{9}$ For more see: Bötticher, K. (1844) 'Die Tektonik der Hellenen'Verlag von Ferdinand Riegel, Potsdam
} 
architecture with regard to their symbolic meaning, specifically the development of the Greek tectonic language. His distinction between a "core-form" (also work-form; abstractly, the actual structural work to be performed) and the "art-form" (its symbolic or artistic representation) became a cornerstone of German tectonic theory, and gave rise to an abundance of theorizing on the application of these concepts to new materials and technologies. ${ }^{10}$

For Bötticher, the reciprocal relationship between Kernform and Kunstform constituted a dynamic interplay between the structure and ornament of architecture. ${ }^{11}$

In classical architectural theory, decoration was the complementary term for a fundamental distinction and was considered within an overall tripartite division of architecture's teachings: distribution, construction and decoration, the three fundamental tasks of architectural design. ${ }^{12}$

According to Schinkel:

The purposefulness of any building can be considered from three principal perspectives: purposefulness of spatial distribution or of the plan, purposefulness of construction or the joining of materials appropriate to the plan, purposefulness of ornament or decoration.

As a response to Schinkel, recent discourse requires a complete separation of the word decoration from the word ornament: one is understood as externally applied and extrinsic, while the other is understood as constitutive and intrinsic. ${ }^{13}$

\section{Ornament as Cultural Performance}

Considering the first enclosures as woven by branches of grass, Semper identified the wickerwork as the essence of the wall. Hence he will conclude:

Textile art, therefore, itself an imitation of ritual, rhythm, and dance - is the source not only of the practical arts, but also architecture; 'The beginnings of buildings coincide with those of weaving.'

This cross-origin of art and architecture from the motifs of pattern-generation in the wickerwork, dance and ornamentation of the bodies gives us the primordial motifs for the development of first built structures, where the light textile walls were transformed into clay tile, brick, or stone walls, transforming the material by retaining the motifs - the patterning and ornamentation.

\subsection{Architecture + Textile $=$ Architextile}

Dating textile structure around 7000 years ago, urged us to believe that the first building materials and structures were textile based. The connection of textile with architecture is ever-intensifying since the first encounter.

Considering the connection Architecture-textile, according to Mark Garcia, it comes in form of a relationship in four most occurring forms: when a textile or textile-based process is used as a metaphor, when a textile-like spatial structure (such as a weave) is produced in architecture, when textiles (or textile composites) are used as a real material in a real building, and where textiles appear in architectural theory and texts. ${ }^{14}$

The relation of textile patterns with detail, ornament, decoration, structure and beauty was strongly influenced by cultural attitudes, religion, geometry and maths, arts, design and crafts.

The concepts and theories through which spatial pattern was theorised include order, hierarchy, organisation, system, scale, proportion, symmetry, balance, complexity, beauty, unity, function, decorum, representation, symbol, joint, nature, expression, imagination and creativity. ${ }^{15}$

\footnotetext{
${ }^{10}$ Mallgrave, H. F. (2006) 'Architectural Theory: An Anthology from Vitruvius to 1870' Blackwell Publishing, p. 531

${ }^{11}$ Hvattum, M. (2004) 'Gottfried Semper and the problem of Historicism', Cambridge University Press, New York, p. 59

${ }^{12}$ Schumacher, P. (2009) 'Parametric Patterns', AD Vol 79/6, Wiley Academy, p. 30

${ }^{13}$ Douglis, E. (2009) 'Autogenic Structures' Taylor\& Francis, Oxon, p. 14

${ }^{14}$ Garcia, M. (2006) 'Architecture + Textiles = Architextiles', AD Vol 76/6, Wiley Academy, p. 13

15 Ibid, p. 9
} 
The theories on patterns are wide and concern of different disciplines. In his search for the Origin of Art and Architecture, Gottfried Semper in his discourse on Dressing and Textile, sees the patterning as structural generative from the process of joining parts together - the knot:

In time, the motif of the knot was developed further in the more complex techniques of the braid, the wreath, the seam, and the weave; all constituting primordial symbols of ordering., symbolising "the primordial chain of being," 16
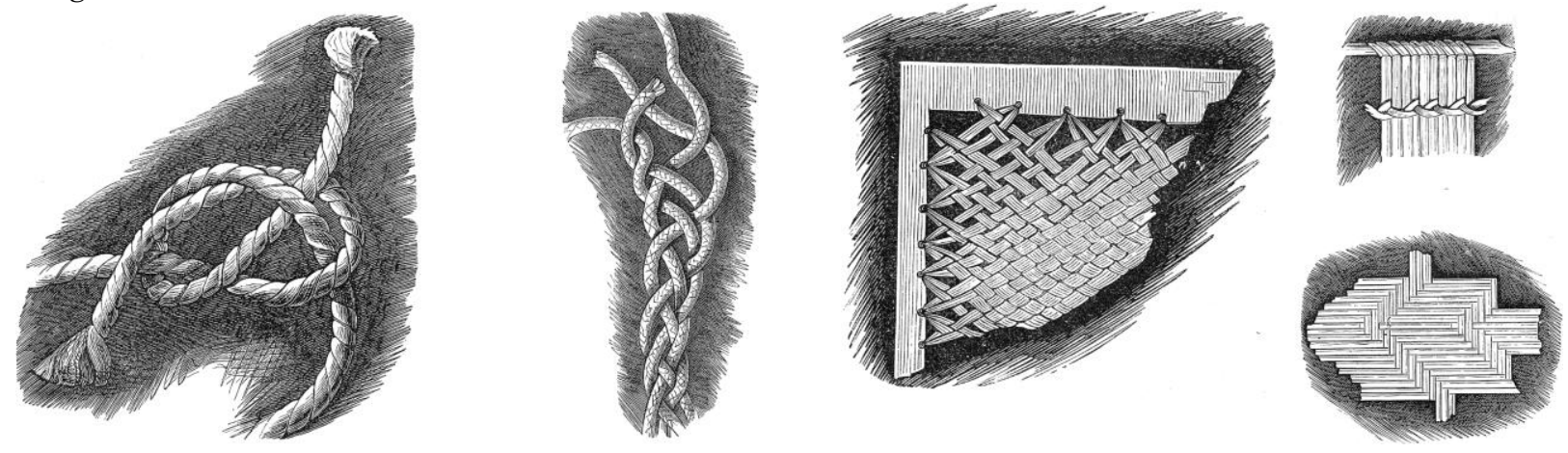

Figure 2.1.1: (left) Knots and braids. Gottfried Semper, Der Stil (2nd ed. 1878), vol. 1, pp. 169-72

Figure 2.1.2: (right) Techniques of weaving. Gottfried Semper, Der Stil (2nd ed. 1878), vol. 1, p. 177

A further connection to architecture and primordial motifs Semper found in the motif of the wall, which he tracked back to the technique of weaving. So the weaving as a patterning process of making an enclosure, a wall, a separation, was in the same time a structural, functional, symbolic and metaphysic representation of rituals. Further more, for Semper these original motifs of art are fused as well with the development of Architecture.

'The beginnings of buildings coincide with those of weaving.' Semper declared.

Taking motifs from nature is a primordial process, but moreover this are not merely copied from nature, but transformed and developed under the aura of human creativity and aesthetics.

Architecture as a Mimesis of Praxis is an Aristotelian paradigm.

\subsection{Ornament and Patterning Architecture}

From the ancient times till now, patterns was far more important than the material stuff that constitutes it.

Rule-based, Geometric patterns have fascinated mankind since ancient times. Artists had an excellent understanding of the generation principles of patterns long before mathematicians devoted deep studies to this subject. A prominent example is furnished by Moorish architecture. In the 13th-century Alhambra Palace in Granada, Spain, we find all the essentially different types of pattern that can be formed by congruent tiles; the mathematical classification has only been achieved in the 20th century. ${ }^{17}$

\section{Islamic Architecture and Ornament}

As known, Islam in itself omits figuration. In this direction, Islamic architecture has constructed a taxonomy of patterns and ornamentation that express and goes along the basic tenet of Islam, not to be misled into an imaginary and idolatrous world.

\footnotetext{
${ }^{16}$ Hvattum, M. (2004) 'Gottfried Semper and the problem of Historicism', Cambridge University Press, New York, p. 67

${ }^{17}$ Pottmann, H. (2009) 'Geometry and New and Future Spatial Patterns'AD Vol 79/6, Wiley Academy, p. 61
} 


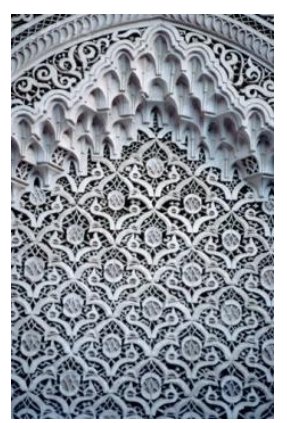

Figure 3.1: (left) Lacework Carvings and Muqarnas, Bahia Palace in Marrakesh Credit: () Carmen Redondo/CORBIS

Figure 3.2: (right) A thirty seven ceramic tile alphabet capable of generating infinite parking configurations throughout the history of Moorish Architecture Credit: () Jean-Marc Castera ${ }^{18}$

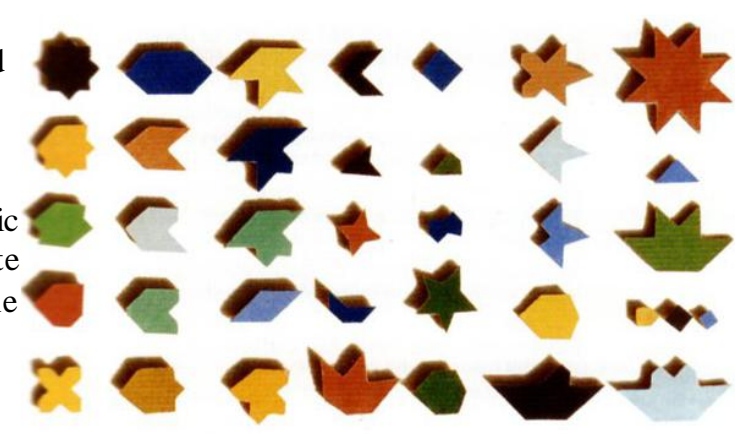

Islamic patterning and ornamentation has recently raised interests among the architects and artists because of its intellectual, mental, cultural and metaphysical bias, not merely decoration and material. In one hand this interest is also related with the shift of huge amount of construction works lead in the East by the Western architects and designers. And in the other hand, the Islamic patterning is becoming generative through digital tools in the articulation of the building envelope through a deep Ornamentation.

By freeing itself of any representation of living things, Islam gave a real constrain to the development of an art and architecture relied on pure inspiration, meaning, geometries, patterns and forms derived from nature. A wide alphabet inspired and derived from nature, created a whole grammar and language which universally spread and come to be accepted as a unique creation of the Muslim World spatially and temporally.

Patterns and Ornaments inspired form Nature and developed in a unique way through the use of geometry created across centuries what is now being known as Arabesque, Islamic Patterns and Islamic Ornaments, which created a definite visual language possessing both vocabulary and grammar.

The concept of Vocabulary and Grammar could be placed in the realm of Structuralist approach to architecture; as structural counterpart to language.

For Saussure, the fact that buildings have regular identifiable components makes it easy, at first sight to speak of the language of architecture and the vocabulary of architecture. ${ }^{19}$

In this realm of structure as a counterpart of a building language, vocabulary and grammar, Eduard Sekler, ${ }^{20}$ in his essay 'Structure, Construction, Tectonics'states:

Through tectonics the architect may make visible, in a strong statement that intensified kind of experience of reality which is the artist's domain - in ourcase the experience of forces related to forms in a building. Thus structure, the intangible concept, is realized through construction and given visual expression through tectonics.

\subsection{Autogenic structures for Mosque design}

Searching for universal as well as local meaning for developing a structural, tectonic and spatial language for Mosque design as a representative built form, in-between theory and design we proposed ornament as a legible and powerful element for creating both conceptual and formal solution for articulation of Mosque design not just in the envelope but more profoundly - structurally. Moreover, modular development approach collapses what seems now to be an artificial separation of structure from ornament. ${ }^{21}$

By defining three categories of Ornamenting used in the Islamic Architecture:

- Geometrical Islamic Patterns

- Vegetal and Floral, and

- Islamic Calligraphy - Arabesque

\footnotetext{
${ }^{18}$ Douglis, E. (2009) 'Autogenic Structures'Taylor\&Francis, Oxon, p. 11

${ }^{19}$ Winters, E. (2007) 'Aesthetics and Architecture' Continuum, New York, 2007, p. 64

${ }^{20}$ Kepes, G. (1965) 'Structure in Art and in Science' George Braziller, New York, 1965, p. 92

${ }^{21}$ Douglis, E. (2009) 'Autogenic Structures' Taylor \& Francis, Oxon, p. 10
} 


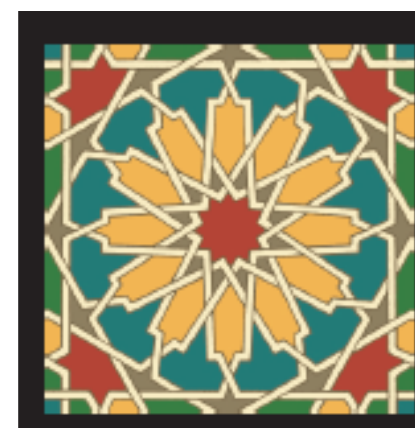

Geometrical

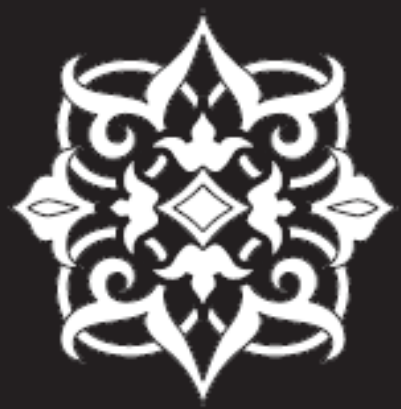

VegetaVFloral

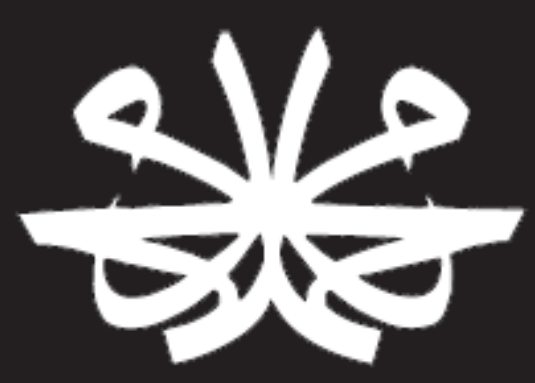

Calligraphy

Figure 3.1.1: Three main categories of generic families of Is lamic Patterns and Ornaments

Our approach was to adopt methods to transform these $2 \mathrm{D}$ patterns into $3 \mathrm{D}$ components, by mining tectonic/structural potentials.

By disintegrating the pattern into layers, unfolding the generic layers, we derive the geometrical entities to be used for composing and transferring them into three-dimensional components. The criteria set for this technique was that, first of all the 3D component should resemble the generic pattern, hence be legible as a Islamic Pattern, the second main is sue was the as sociative and connective potentials of the $3 \mathrm{D}$ component for an as sociative/blend ed 'population' of a component on a spatial envelope.
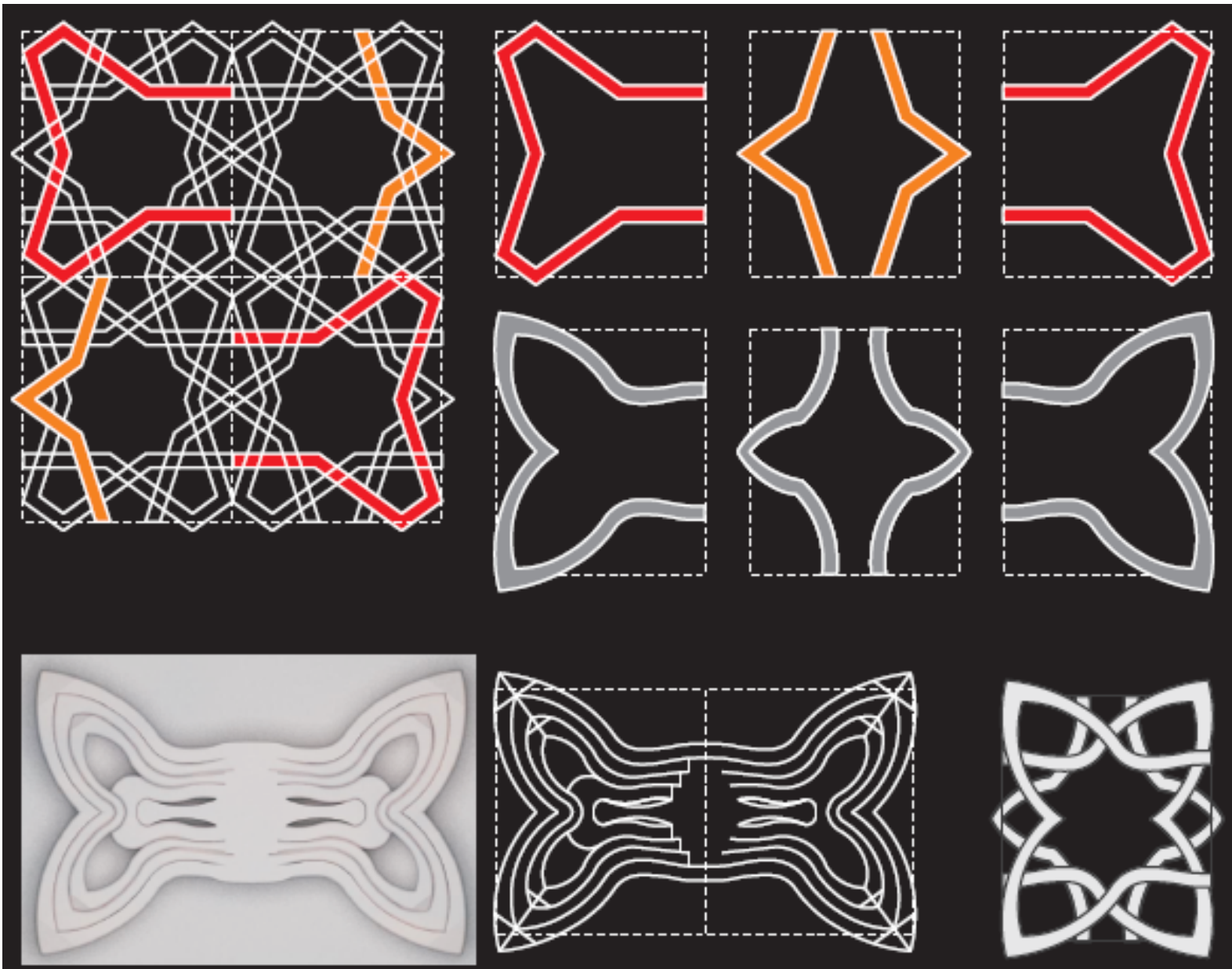

Figure 3.1.2: Transforming the 2D Is lamic Pattern into a 3D associative structural component (Credit: (C) B. Shyqeriu, Synergic Spaces - MOSQUE) 
By using digital tools which automate repetitive tasks - population, multiplication, deformation, association, blending and scaling - an intricate systemappears, by dissolving the ornament into structure, interacting material, skin, form and space, into a synergic whole.

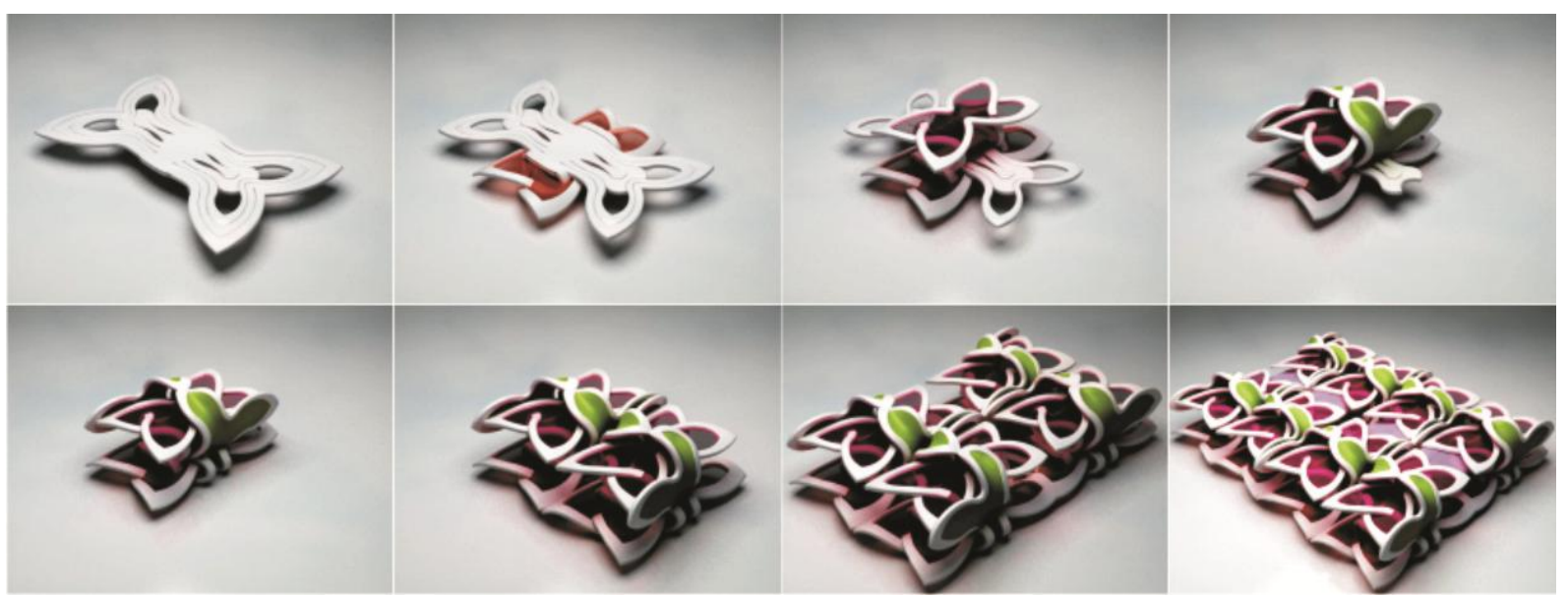

Figure 3.1.3: Mining structural potentials of Ornament / Component - folding, as sociating, populating and dissolving (Credit: (O B. Shyqeriu, Synergic Spaces - MOSQUE)

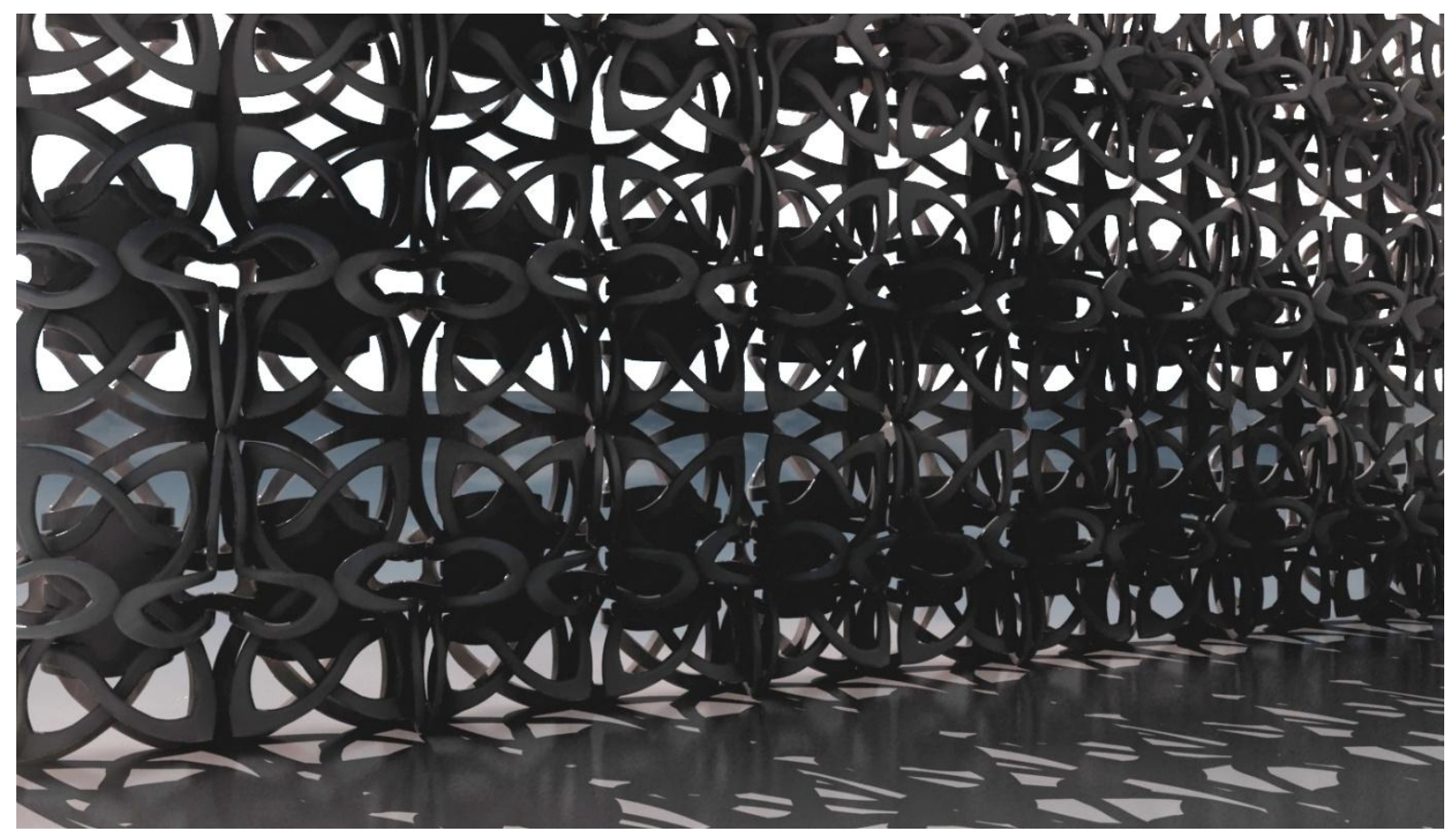

Figure 3.1.4: "Deep Ornamentation" wall, dissolution of ornament into structure and vice-versa (Credit: () B. Shyqeriu, Synergic Spaces - MOSQUE)

Our work maintains the position that Ornamentation in Islamic arts and architecture has certain level of ambiguity due to several implications and tendencies to give meaning to it. Moreover we inherit a sharp distinction through the potency of our recent Modernist past; of what is ornament and pure structure. Furthermore, in modernism we had a two fold approach towards ornament, first by promoting ornament in new way through industrial advances, and discrediting it theoretically and practically as superfluous and regressive. 


\section{Discrediting and Promoting Ornament}

The decorative patterning of surfaces was still taken for granted all the way through the 19th century until, suddenly; Modernism opted for the clean, white wall - in the footsteps of the clean, white shirt. The first examples of unadorned, naked architecture were causing public scandals, most notoriously Adolph Loos' Haus am Michaelerplatz (1898) in Vienna. ${ }^{22}$

Loos soon won the argument. The re-evaluation of values was extreme: ornament signified backwardness.

According to Loos, the evolution of culture is synonymous with the removal of ornament. ${ }^{23}$

"Ornament and Crime" was mostly read as "Ornament is Crime" 24

Connecting ornamentation with tattoos, criminals, degeneration, waste of money and material, Loos extends this to

Architecture, through banishing ornament that was created at that time, as superfluous which bears no relation to the current time and that it has no potential for development.

Not surprisingly the condemnation of ornament does not include a structural use of classical ornament, which Loos often affirms in his writings and practices in his architecture. In this sense, given his taste for ornate materials, especially in the interiors, the architectural historian Harry Mallgrave has concluded that Loos 'was, at heart, an ornamentalist ${ }^{25}$

Hence, the stereotyping of Modernism as dogmatically anti-pattern and against decoration and ornament is inaccurate, as numerous examples attest. ${ }^{26}$

Viewing patterns and ornamentation far from merely decoration, new approaches are mining cultural and political possibilities, as well as ecological. The approach on ornament as structure even though has earlier precedents like Viollet le Duc (fig. 4.1), the full potentials will be waiting to be revealed recently with the advent of technique and technology and new approaches in design, where performance takes a crucial place.
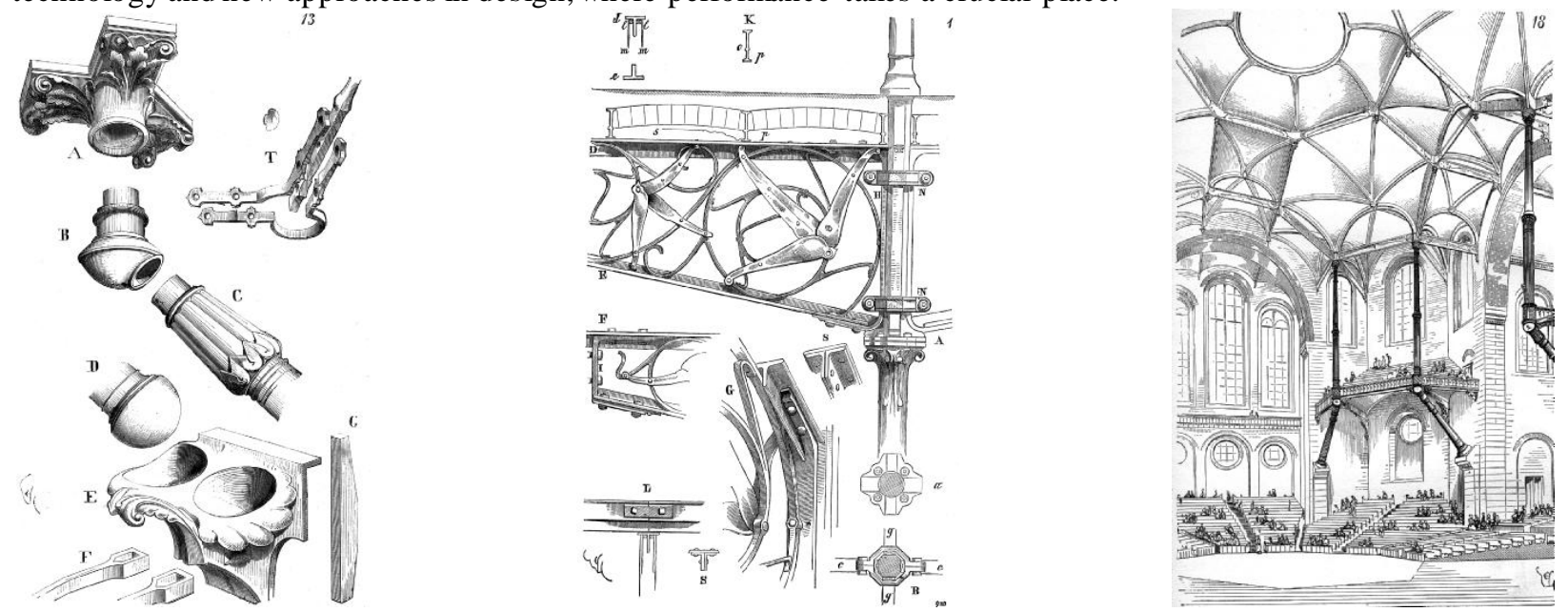

Figure 4.1 Left: Organically conceived structural detail, hypothetical great hall, Middle: Iron truss with decoration incorporated, Right: Iron frame construction, hypothetical assembly hall for three thousand: Viollet-le-Duc (Discourses). ${ }^{27}$

Even though Modernism was promoting the white wall and the preciseness of engineering, patterning and ornamentation was still a strong articulating feature of both structure and building envelope. The use of patterns is visible in the writing and works of many Modernists; Le Corbusier, the Smithsons, Metabolists. Mies van der Rohe and Frank Lloyd Wright (fig. 4.2; 4.3; 4.4) are probably more notable in the use of ornament in their work. Mies used columns in such a way as to express and articulate the tectonics and aesthetic values of the structure, hence tectonics expresses the ornament as an Art-form. So, the use of columns in the corners of many high-rise buildings

\footnotetext{
${ }^{22}$ Schumacher, P. (2009) 'Parametric Patterns', AD Vol 79/6, p. 32

${ }^{23}$ Ibid, p. 32

${ }^{24}$ Foster, H. (2004) 'Prosthetic gods' MIT Press, Massachusetts, p. 56

${ }^{25}$ Ibid, p. 99

${ }^{26}$ Garcia, M. (2009) 'Prologue for a History, Theory and Future of Patterns of Architecture and Spatial Design' AD Vol 79/6, Wiley Academy, p. 12

${ }^{27}$ Hearn, F. (2003) 'Ideas that shaped the buildings'MIT press, Massachusetts, p. 228 - 231
} 
by Mies, which are not structural, emphasizes the Core-form of the building, by rendering the patterns of these columns as a tectonic expression of the diagram of forces, which express themselves as ornament.

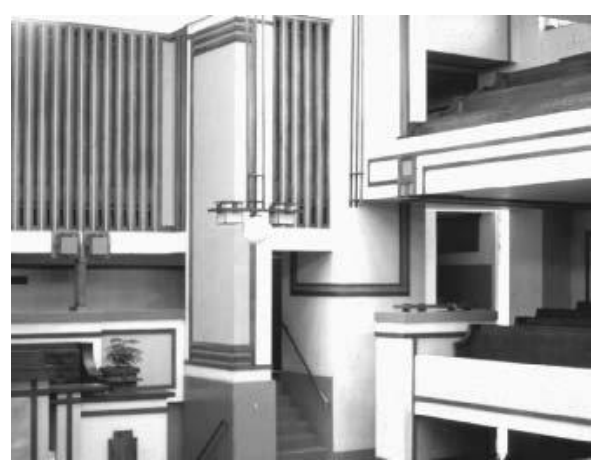

Frank Lloyd Wright in the other hand uses Ornament in a more fluent, textile-way.

Wright never advocated the direct revivalism or imitation of traditional ornaments but chooses to select his own motifs and composition of ornamentation.

In the Unity Temple, Wright displays his powers of integrating ornament into the building's exterior characteristics and he had also rendered the interior ornamentation through the ceiling moldings, fixtures and wall paneling.

Figure 4.2: Integration of structure and décor; Frank Lloyd Wright, Unity Temple, Chicago ${ }^{28}$

Promoting the Organic Architecture, probably the most notable work of Wright in our relevance to Structure and Ornament is the "textile block", Ennis House.

The "textile block" method of construction consisted of stacking concrete blocks three inches thick, cast in moulds, next to and atop one another without visible mortar joints.
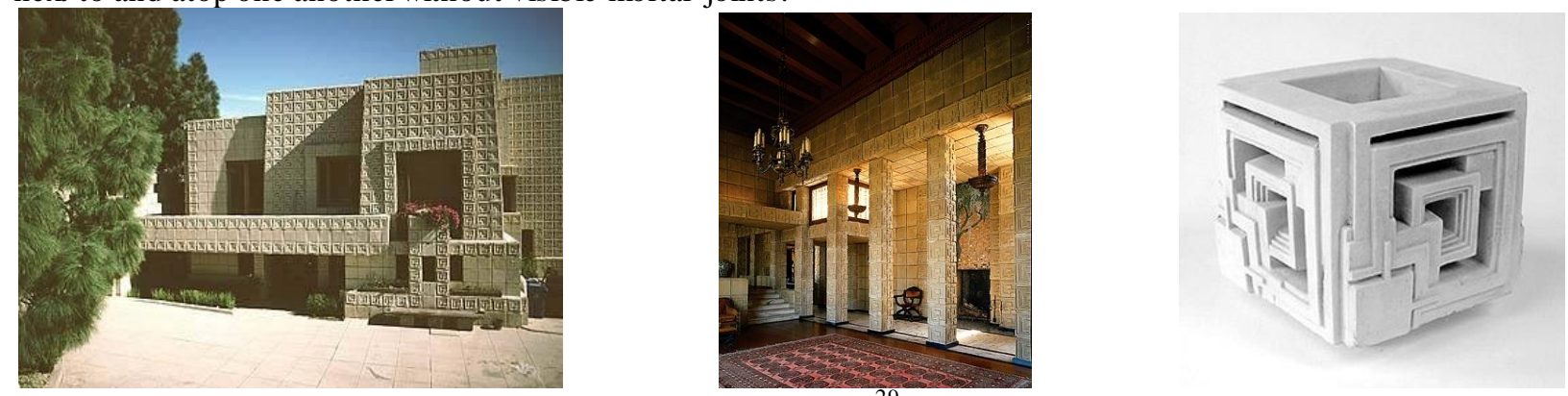

Figure 4.3: (left and middle) Ennis House Exterior and Interior ${ }^{29}$

Figure 4.4: (right) Ennis House "Textile Block" 30

Here Wright melts the idea of the textile softness and fluidity into the structure and skin of the building. The ornament is the prevailing, the structure is the ornament.

The use of Concrete in the $20^{\text {th }}$ century and the advances on engineering calculation of it led to and immense use of it in innovative ways.

Perhaps one of the most relevant pioneers of concrete Structures is Pier Luigi Nervi (fig. 4.5), who used his understanding of materials to create incredibly elegant structures.

What it is rendered in Nervi's works as ornamentation is the structure itself, the diagram of forces that comprise the construction, expressing it through tectonic articulation of the material. Moreover, Nervi explored the possibility of topologically deforming patterns in order to accommodate the differential behaviours of structures.

For Nervi "Building correctly is synonymous with truth to function, technique and economy and is the necessary and sufficient condition for satisfactory aesthetic results."

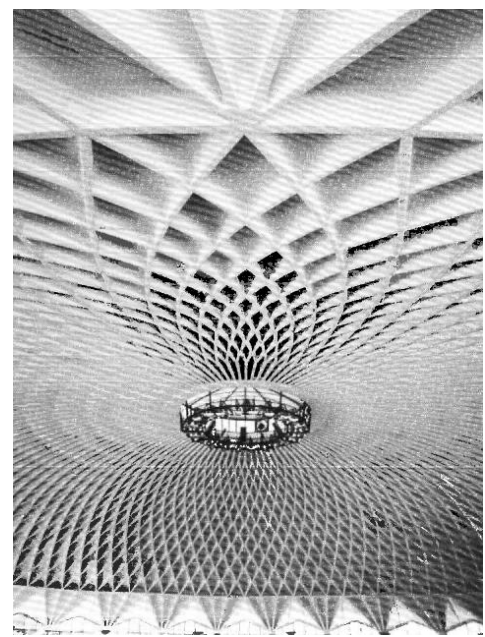

Figure 4.5: Pier Luigi Nervi. Small Sports Palace (Palazzetto dello Sport) - the dome from the interior. ${ }^{31}$

\footnotetext{
28 Ibid., p. 243

${ }^{29}$ Thompson, I. (1999) 'Frank Lloyd Wright: A Visual Encyclopedia'Thunder Bay Press, California

${ }^{30}$ Design Collections, at: http://www.maclinstudio.com/frllwrenhola.html
} 
From Semper to Loos and Nervi, through theoretical and practical/ operative approaches, ornament and struc ture have had a great concern, while the recent breakthrough comes with new paradigm in the focal point. The new Paradigms on Structure view it in close relation to skin; materiality, form and space, as well as ornamentation, as systems that act upon each other. These Paradigms come from Biology/Natural Systems, which treat structure as Autogenic ${ }^{32}$ in the process of Morphogenesis and Self-Organisation. ${ }^{33}$

\section{Performative Energies in Autogenic Structures - New Biological Paradigm}

Taking reference form nature as a paradigm is a creative act of mimesis. This theme of mimesis we already elaborated in the realm of Classicism, where, referring Bötticher; the principles of Greek tectonics were 'fully identical with the principles of creative nature'. ${ }^{34}$ Latter on, many theorists, engineers and architect would return to nature principles. Buckminster Fuller writings in the 1960s provided an inspiring bridge between our comprehension of the structural principles of nature and the potential application of this knowledge to creation of man-made forms. ${ }^{35}$ However, our understanding of natural principles has extended ever since.

Alongside the potentials for a Biological Paradigm for Architectural Design, there are a number of crucial challenges and difficulties; in terms of materiality, composition, behaviour, performance and lifecycle. Unlike engineering materials, Natural materials develop under load, and the intricate structure of biological materials is an evolutionary response. ${ }^{36}$

The challenging paradigm of nature for architectural structures relies in the very materiality of the biological system. As the structure and material in the biological systems are grown, hence are in separable. These differences can be revealed as explored by Fratzl et al. in 'Nature's hierarchical material' (table 5.1). ${ }^{37}$

The engineering principles of biological systems can be abstracted and applied to the design of artefacts and buildings, a process known as biomimetics.

Biomimetics is essentially interdisciplinary, a series of collaborations and exchanges between mathematicians, physicists, engineers, botanists, doctors and zoologists. The logic of biomimes is, stands for abstracting principles from the way in which biological processes develop a natural material system, applying analogous meth ods in an industrial context, and using stronger materials to manufacture a material that has no natural analogue. ${ }^{38}$

Biological Materials

Engineering Material

\begin{tabular}{|c|c|}
\hline Light Elements dominate: & Large Variety of Materials \\
$\mathrm{C}, \mathrm{N}, \mathrm{O}, \mathrm{H}, \mathrm{Ca}, \mathrm{P}, \mathrm{S}, \mathrm{Si}, \ldots$ & $\mathrm{Fe}, \mathrm{Cr}, \mathrm{Ni}, \mathrm{Al}, \mathrm{Si}, \mathrm{C}, \mathrm{N}, \mathrm{O}, \ldots$ \\
\hline Growth & Fabrication \\
\hline by biologically controlled & from melts, powders, solutions, \\
self-assembly (approximate design) & etc. (exact design) \\
\hline
\end{tabular}

r2

${ }^{31}$ Nervi, P. L. (1965) "Aesthetics and Technology in Building" trans. form Italian by Robert Einaudi, Harward University Press, Cambridge. p. 138

${ }^{32}$ Douglis, E. (2009) 'Autogenic Structures' Taylor \& Francis, Oxon, p. 15

${ }^{33}$ For more see: Weinstock, M. (2006) 'Self-Organisation and Material Constructions' AD 76/2 = 180, Wiley Academy, p. 34-41

${ }^{34}$ Mallgrave, H. F. 'The Architect's Brain: Neuroscience, Creativity and Architecture' Wiley-Blackwell, 2010, p. 66

${ }^{35}$ Kepes, G. (1965) 'Structure in Art and in Science' George Braziller, New York, p. V

${ }^{36}$ Weinstock, M. (2006) 'Self-Organisation and Material Constructions' AD 76/2 = 180, Wiley Academy, p. 35

${ }^{37}$ Fratzl, P., et al. (2007) 'Nature's hierarchical materials' Progress in Materials Science 52, p. 1266 (http://dx.doi.org/10.1016/j.p matsci.2007.06.001)

${ }^{38}$ Weinstock, M. (2006) 'Self-Organisation and the Structural Dynamics of Plants' AD 76/2 = 180, Wiley Academy, p. 27 


\begin{tabular}{|c|c|}
\hline $\begin{array}{c}\text { Hierarchical Structuring } \\
\text { at all size levels }\end{array}$ & $\begin{array}{c}\text { Forming (of the part) and } \\
\text { Micro-structuring (of the material) }\end{array}$ \\
\hline $\begin{array}{c}\text { Adaptation } \\
\text { of form and structure to the function }\end{array}$ & $\begin{array}{l}\text { Selection of material } \\
\text { according to function }\end{array}$ \\
\hline $\begin{array}{c}\text { Modeling and Remodeling: } \\
\text { Capability of adaptation to changing } \\
\text { environmental conditions. } \\
\end{array}$ & \multirow{2}{*}{$\begin{array}{c}\text { Secure Design } \\
\text { (considering possible maximum loads as } \\
\text { well as fatigue) }\end{array}$} \\
\hline $\begin{array}{c}\text { Healing: } \\
\text { Capability of self-repair }\end{array}$ & \\
\hline
\end{tabular}

Table 5.1: Biological and engineering materials are governed by a very different choice of base elements and by a different mode offabrication. From this are resulting different strategies for materials choice and development. (adapted from Fratzl et al., 2007)

Exploring the hierarchical levels in plants and sea organisms, researches have created a better understanding of structure in relation to other systems and subsystems. In this relation, as structure is grown together with other systems, it is embedded into the materiality, form, behaviour and performance. Moreover the ornamentation we see in plants and animals is a direct consequence of growth and materiality rather a mere decoration.

This understanding is crucial for our theme of Ornament as Structure, which has recently raised interest of many designers, taking the Paradigm of Natural/Biological system, where Ornament is structured during the process of growth.

\subsection{Ornament as Structure}

Glass is widely used as a building material in the biological world, despite its fragility. ${ }^{39}$

The skeleton of the glass sponge Euplectella is a remarkable hierarchical textile-like structure.

Hierarchical structuring allows the construction of large and complex org ans based on much smaller, often very similar, building blocks. Moreover, hierarchical structuring allows the adaptation and optimization of the material at each level of hierarchy to yield outstanding performance. ${ }^{40}$

Comprised of seven hierarchical levels, the macroscale structure of Euplectella, with horizontal, vertical and diagonal lattices / struts, is ideal for resisting tensile and shearing stresses. ${ }^{41}$ Hence, the structural motifs, from ornamented ridges present the structural performance of Euplectella. In most of the cases, nature uses brittle and "cheap" materials to materialize the hierarchical structure, as in the case of glass sponge. A hierarchical structure implies that building blocks of different sizes have to be joined to make up a useful material. ${ }^{42}$ In a microscale, the glass sponge structure is "grown" from silica spicules ( 5 to $5 \mu \mathrm{m}$ in diameter) embedded in a layered silica matrix ${ }^{43}$ (fig 5.1.1).

\footnotetext{
${ }^{39}$ Aizenberg, J. et al. (2005) 'Skeleton of Euplectella sp.: Structural Hierarchy from the Nanoscale to the Macroscale'SCIENCE V 309, 8 JULY 2005, p. 275

${ }^{40}$ Fratzl, P. (2007) 'Biomimetic materials research: what can we really learn from nature's structural materials?' J. R. Soc. Interface 2007 4, p. 639-640. (doi: 10.1098/rsif.2007.0218)

${ }^{41}$ Aizenberg, J. et al. (2005) 'Skeleton of Euplectella sp.: Structural Hierarchy from the Nanoscale to the Macroscale' SCIENCE V 309, 8 JULY 2005, p. 276

${ }^{42}$ Fratzl, P. (2011) 'Artful interfaces within biological materials'Materials Today, March 2011, V 14, Number 3, p. 70 (ISSN:13697021 @ Elsevier Ltd 2011)

${ }^{43}$ Aizenberg, J. et al. (2005) 'Skeleton of Euplectella sp.: Structural Hierarchy from the Nanoscale to the Macroscale' SCIENCE V 309, 8 JULY 2005, p. 276
} 

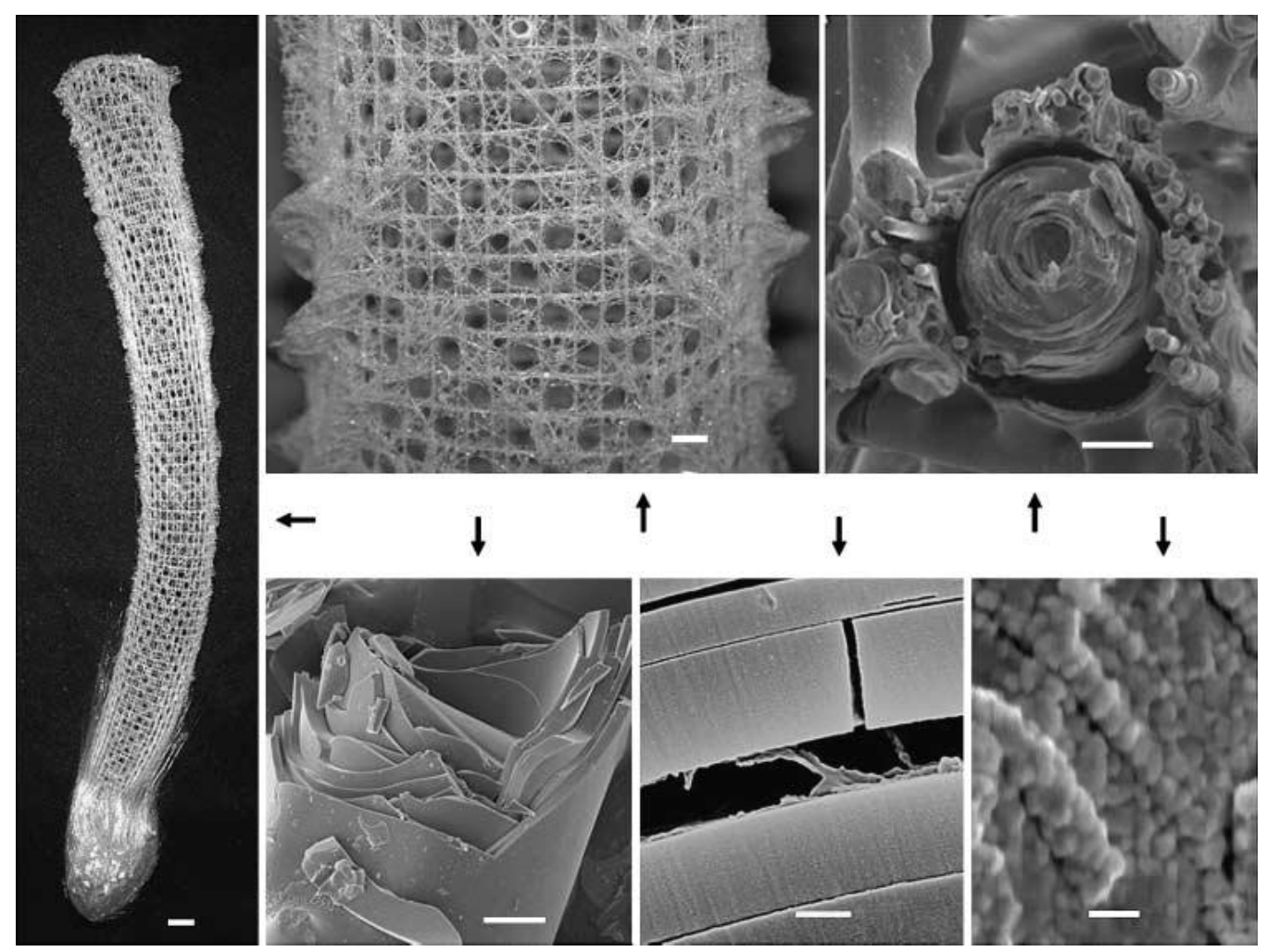

Figure 5.1.1: Several levels of hierarchy in the structure of the skeleton of the glass sponge Euplectella (Source / credit: () Fratzl, P. (2007) Biomimetic materials research: what can we really learn from nature's structural materials?. J. R. Soc. Interface 2007 4, p. 639 (doi: 10.1098/rsif.2007.0218)

\subsection{Survival of the Cheapest}

Organisms use what is available in their environment: availability of energy source, material, cooperation etc. Simple materials are used, and so information is needed for developing these to high performance structures. ${ }^{44}$
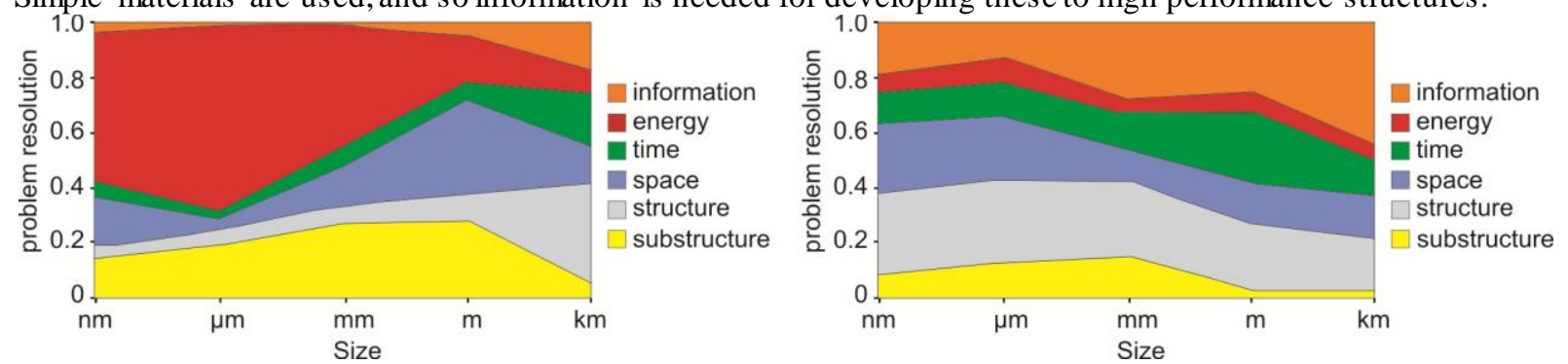

Figure 5.2.1: (left) Engineering TRIZ solutions arranged according to size/hierarchy. (right) Biological effects arranged according to size/hierarchy (Source / credit: @) Vincent, J. et al. (2006) 'Biomimetics: its practice and theory' J. R. Soc. Interface 2006 3, p. 478 (doi: 10.1098/rsif.2006.0127)

As investigated by Vincent et al., if we look at problem solving in Engineering, respectively technology, at size levels of up to $1 \mathrm{~m}$, the most important variable for the solution of a problem is manipulation of energy usage (up to $60 \%$ of the time), closely followed by use of material (fig. 5.2.1, left). Thus, faced with an engineering problem, the tendency is to achieve a solution by changing the amount or type of the material or changing (usually increasing) the energy requirement. But in biology the most important variables for the solution of problems at these scales are information and space (fig. 5.2.1, right). In Biological systems the main variety of function is achieved by

${ }^{44}$ Gruber, P. (2011) 'Biomimetics in Architecture: Architecture of Life and Buildings'Springer-Verlag, Vienna, p. 97 
manipulations of shape and combinations of materials at larger sizes achieved by high levels of hierarchy, where energy is not an issue. This is a very subtle biomimetic lesson. Instead of developing new materials each time we want new functionality, we should be adapting and combining the materials we already have. ${ }^{45}$

Vincent et al., investigates that analysis using TRIZ shows that there is only $12 \%$ similarity between biology and technology in the principles which solutions to problems illustrate, and while technology solves problems largely by manipulating usage of energy, biology uses information and structure, two factors largely ignored by technology.

So, nature uses "cheap" materials to grow highly performative structured materials and materialized structures, by using less energy and much more information compared to Engineering approach, hence in nature survives the cheapest. Further, nature optimizes these structures for effectiveness and energy efficiency during grow and their life-span. Moreover, nature' optimized structures represent highly ornamented motifs.

\subsection{Ornamentation and Structural Optimization}

All over nature we encounter endless forms and structures which are highly optimized, some of the natural / biological systems are visual representatives of their ornament-like structures, while some conceal their intricate structure in lower hierarchical levels, like bone and wood.

Hence, structural optimization occurs on three different levels: on the global scale (structural system), the local scale (structural component) and the micro scale (material). ${ }^{46}$ We have seen these three different levels in the structure of skeleton of glass sponge - Euplectella.

The objective of structuraloptimization is to maximize the performance of a structure or structural component. It is driven by limited resources, environmental impact and technological competition, which demand lightweight, low cost and high-performance structures. ${ }^{47}$

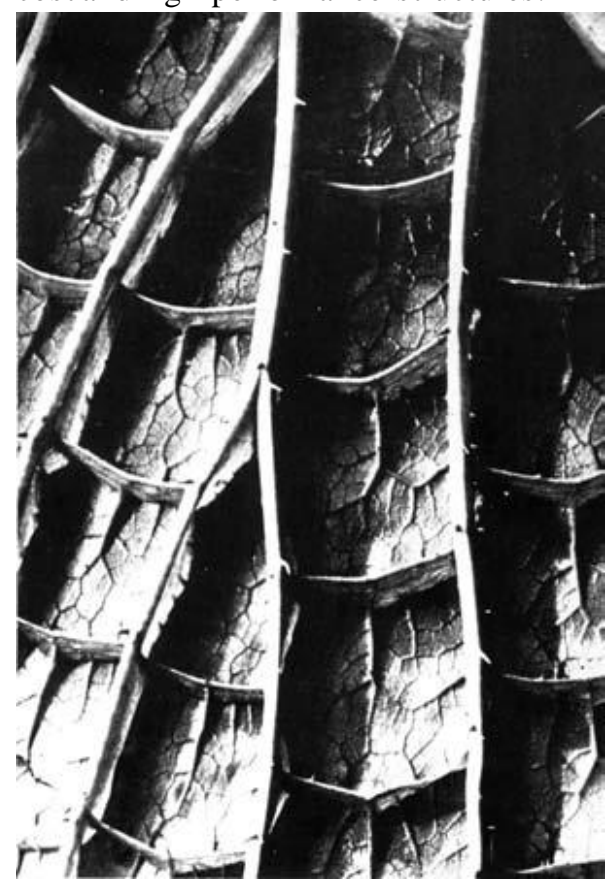

The feed-back loop in nature, where material, structure and form are grown provides a subtle paradigm for the actual linear design in architecture (form - structure - material). Moreover, natural/ biological structures have always inspired mankind, especially artist, architects and engineers, while in the same time their literal interpretation has created a gap of pitfalls and fallacies.

The Victoria Regia water lily (fig. 5.3.1) is an early example which provided Paxton with the inspiration for the ridge-and-furrow roof construction of the Great Exhibition building, even though in our sight and understanding this represents only a visual analogy without any profound connection with the specific ornament-like, lattice-work of water lily ridges.

Figure 5.3.1: Underside of the leaf of the Victoria Regia water lily (Source: Steadman, Ph. (2008) 'The Evolution of Design: Biological Analogy in Architecture and the Applied Arts' Routledge, New York, p. 160).

New tools of analyzing, synthesizing and generating surfaces, forms and structures are giving new breakthrough to optimization of natural patterns, materials, structures and forms as systems that act upon each other.

\footnotetext{
45 Vincent, J. et al. (2006) 'Biomimetics: its practice and theory'J. R. Soc. Interface 2006 3, p. 477 - 478 (doi: 10.1098/rsif.2006.0127)

${ }^{46}$ Stach, E. (2010) 'Structural morphologyand self-organisation'Carpi, A \& Brebbia C. A. (eds.) Design \& Nature V, WIT Press, Southampton, p. 31

${ }^{47}$ Ibid., p. 29
} 
Claus Mattheck from the Institute of Material Research II in Karlsruhe has used innovative digital methods and tools for optimization based in Finite Element Method (FEM) called: Computer-Aided Optimization (CAO), Soft Kill Option (SKO), etc. ${ }^{48}$
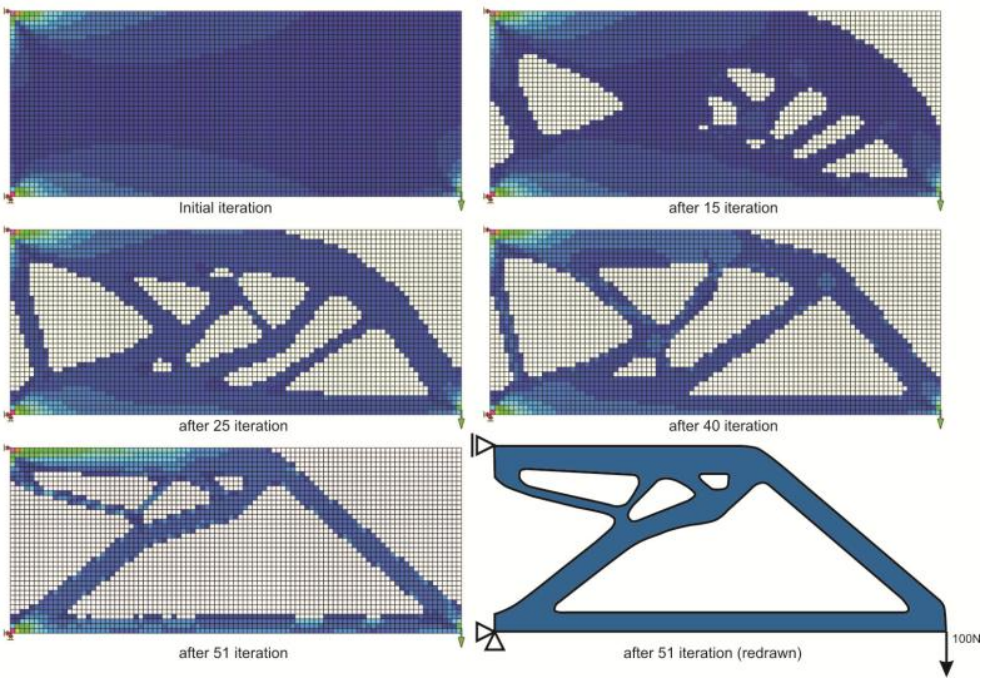

Figure 5.3.2: BESO optimization with 200 maximu $m$ iterations, optimization achieved after 51 iterations with $60 \%$ volume fraction. (Credits: (C) B. Shyqeriu)

The optimization of structural systems (fig. 5.3.2) in $2 \mathrm{D}$ or $3 \mathrm{D}$, in one hand provides analytical approach towards profound understanding how natural/ biological systems grow and perform, while in the other hand an opportunity to transfer this knowledge through instrumentalising it into engineering and architectural operative information.

Moreover, alongside optimization, another paradigm is taken from nature - integration of architectural components and systems into hybridized supersystems - where distinction of structure and performative ornamentation is totally irrelevant.

\subsection{New Frontiers: Hybridization of Components - Ornament becoming Performative Structure}

The synergetics of systems and subsystems in Natural / Biological Systems and Structures are recently being explored as a Paradigm for Integration of technology, especially services of the building with the over all systems, hence the performace and aesthetics of the building. Where structure ands and ornamentation begins is blurred within the performance of the building. As a result, the significant emphasis on the structuring logic of tectonic is resulting in a 'new structuralism' in design. ${ }^{49}$

The EMERGENT research group has conducted extensive research in the realm of "Extreme Integration" Fig. 5.4.1 reveals an attempt on hybridising structural, mechanical and lighting systems, to avoid expressing the literal image of technology in favour of ambient atmospheric effects. Supercolumns become hybrid ducts, while a pattern of micro-pleats runs along surfaces, housing a heat-exchange systemfor cooling. At night, the beam ducts glow from behind the glass skin, creating elegant colour effects and gauzy silhouettes. ${ }^{50}$

\footnotetext{
${ }^{48}$ Mattheck, C. (1998) 'Design in Nature: Learning from Trees' trans. William Linnard, Springer - Verlag, Berlin, P. $32-42$

${ }^{49}$ Architectural Design (2010) 'The New Structuralism: Design, Engineering and Architectural Technologies' Vol 80/4, Wiley Academy, p. 17

${ }^{50}$ Wiscombe, T. (2010) 'Extreme Integration'AD Vol 80/2, Wiley Academy, p. 84-85
} 

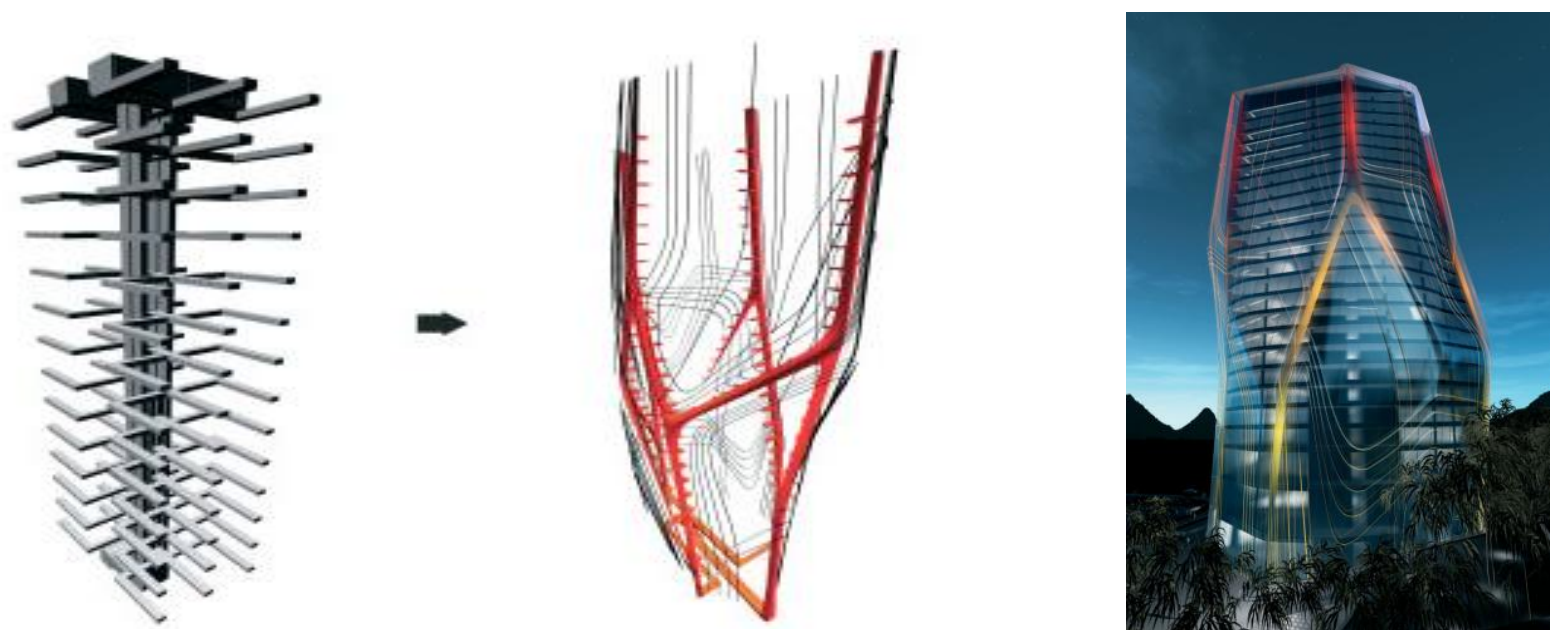

Figure 5.4.1: EMERGENT, Guiyang Office Tower, Guiyang, China, 2008, (Credits: ( ) Architectural Design (2010) 'Exuberance' Vol 80/2, Wiley Academy, p. 84 - 85)

More radically exploring the systems and subsystems of the architectural species as folding upon each other, is brought by exploring the integration of 'air flow', 'fluid flow' and 'glow' togetherwith ornamentation in the structure, materialis ation and architectural space (fig. 5.4.2). ${ }^{51}$

The examples shown from the EMERGENT group provide a subtle argument for ornamentation as a natural outcome of the hybridis ation of architectural systems and components, a paradigm which comes from natural/ biological systems.
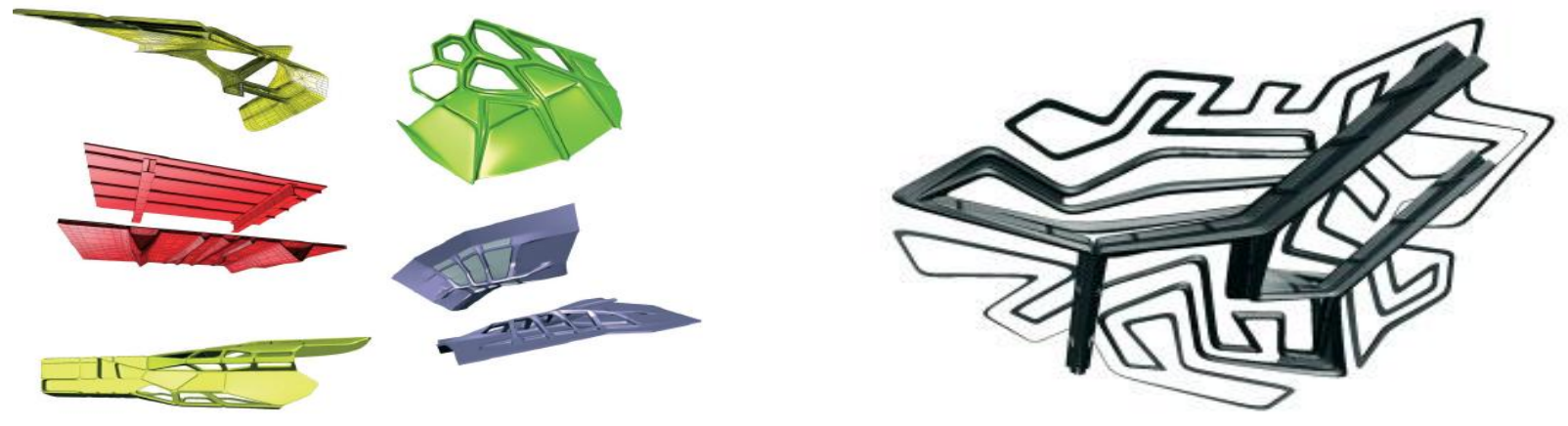

Figure 5.4.2: (left) EMERGENT, the Menagerie, 2006 - Integration of "air flow" ducts within a hybridized component with the structure of the building. (right) EMERGENT, Lizard Panel Facade, 2009 - Façade prototype combining a greywater capture systemwith an algae photo-bioreactorsystemin a way that produces structuralas well as ornamental effects. (Credits: (C) Architectural Design (2010) 'Exuberance' Vol 80/2, Wiley Academy, p. 80 83)

Moreover, the performative capacities of ornament give another argument for reconsidering the arguments that lead to discrediting it in the past.

Following this line, Evan Douglis laid the following argument: "If ornamentation is to fully return from its banishment, it will only do so as an internally generated feature essential to the expression of the whole. More bluntly, it needs to be autogenic". 52

\footnotetext{
${ }^{51}$ Ibid., p. 82

${ }^{52}$ Douglis, E. (2009) 'Autogenic Structures' Taylor \& Francis, Oxon, p. 14
} 
Freeing up the Ornament from banishment and clichés will render it back to its potentials for representatio nal capabilities for surface articulation as Culturally Performative as well as Performative Energies of Ornament as Structure.

\section{Conclusions}

The interaction between Architecture and Ornament - an old coupling - has now begun to develop very dramatically. One of the reasons is the grown interest in performance as a cultural and material approach to Architectural Design. Moreover, the primordial interaction in-between architecture and textile as investigated by Semper, has created a fertile ground for historical and theoretical approaches towards the bias of structure (Kernform) and non-structure (Kunstform) of Architecture. Recently the proliferation of digital avant-garde has raised emphasized interests in building tectonics by exploring and parametricising patterns and ornaments for articulation of building envelopes. With this background in the scope, this research paper has attempted to provide a straight forward link between three disciplines involved: Cultural Sciences, Architecture and Material Scien ces, with the focal point on Ornament and/ as Structure.

The Arab-Is lamic Architecture, as shown in this paper provides an immense vocabulary and grammar of highly rulebased patterns and ornaments derived from natural motifs, which vocabulary we have in vestigated to create autogenic generic structural components for Mosque design. This approach provides potentials for high Cultural Performance as well as structural and spatial. The use of "textile blocks" by Frank Lloyd Wright could be seen in this line as well.

Alongside Cultural Performance, ornament is recently taken through a New Biological Paradigm of "Extreme Integration" where ornament becomes structure through maximizing information and minimization of energy usage by optimized performative structures.

Performative Energies, as well as Performative Cultures are immense potentials for Ornament to fully return from its banishment and become Autogenic.

\section{References and Literature}

1. Aizenberg, Joanna et al. 'Skeleton of Euplectella sp.: Structural Hierarchy from the Nanoscale to the Macroscale' SCIENCE V 309, 8 JULY 2005

2. Architectural Design 'Architextiles' AD, Vol 76/6, Wiley Academy, 2006

3. Architectural Design 'Exuberance' AD, Vol 80/2, Wiley Academy, 2010

4. Architectural Design 'Techniques and Technologies in Morphogenetic Design' AD, Vol 76/2, Wiley Academy, 2006

5. Architectural Design 'The New Structuralism: Design, Engineering and Architectural Technologies' AD, Vol 80/4, Wiley Academy, 2010

6. Architectural Design 'The Patterns of Architecture' AD, Vol 79/6, Wiley Academy, 2009

7. Bötticher, Karl 'Die Tektonik der Hellenen” Verlag von Ferdinand Riegel, Potsdam, 1844

8. Douglis, Evan 'Autogenic Structures' Taylor \& Francis, Oxon, 2009

9. Foster, Hal 'Prosthetic gods' MIT Press, Massachusetts, 2004

10. Fratzl, Peter 'Artful interfaces within biological materials' Materials Today, March 2011, V 14, Number 3 (ISSN:1369 7021 C Elsevier Ltd 2011)

11. Fratzl, Peter 'Biomimetic materials research: what can we really learn from nature's structural materials?' $J$. R. Soc. Interface 2007 4, (doi: 10.1098/rsif.2007.0218)

12. Fratzl, Peter et al. 'Nature's hierarchical materials' Progress in Materials Science 52, Elsevier, 2007 (http://dx.doi.org/10.1016/j.pmatsci.2007.06.001)

13. Gruber, Petra 'Biomimetics in Architecture: Architecture of Life and Buildings' Springer-Verlag, Vienna, 2011

14. Hearn, Fil 'Ideas that shaped the buildings' MIT Press, Mas sachusetts, 2003 
15. Hvattum, Maria 'Gottfried Semper and the problem of Historicism' Cambridge University Press, New York, 2004

16. Kepes, Gyorgy 'Structure in Art and in Science' George Braziller, New York, 1965

17. Loos, Adolf 'Ornament and Crime: Selected Essays' trans. Michael Mitchell, Ariadne Press, Riverside, California, 1998

18. Mallgrave, Harry Francis ‘Architectural Theory: An Anthology from Vitruvius to 1870’ Blackwell Publishing Ltd., Oxford, 2006

19. Mattheck, Claus 'Design in Nature: Learning from Trees' trans. William Linnard, Springer - Verlag, Berlin, 1998

20. Nervi, Pier Luigi 'Aesthetics and Technology in Building' trans. form Italian by Robert Einaudi, Harward University Press, Cambridge, 1965

21. Semper, Gottfried 'Der Stil in den Technischen und Tektonischen Künsten oder Praktische Aesthetik' $2^{\text {nd }}$ ed., Vol. 2, Friedr Bruckmann's Verlag, Müchen, 1879

22. Speltz, Alexander 'Styles of Ornament' Regan Publishing Corporation, Chicago, 1923

23. Stach, E. 'Structural morphology and self-organisation' Carpi, A \& Brebbia C. A. (eds.) Design \& Nature V, WIT Press, Southampton, 2010

24. Steadman, Philip 'The Evolution of Design: Biological Analogy in Architecture and the Applied Arts' Routledge, New York, 2008

25. Thompson, Iain 'Frank Lloyd Wright: A Visual Encyclopedia' Thunder Bay Press, California, 1999

26. Vincent, Julian F.V. et al. 'Biomimetics: its practice and theory' J. R. Soc. Interface 20063 (doi: 10.1098/rsif.2006.0127)

27. Winters, Edward 'Aesthetics and Architecture' Continuum, New York, 2007 